\title{
Effect of Chronic Administration of Lead (Pb) On Feeding Behavior and Weight Gain among Wistar Albino Rats
}

\author{
${ }^{1}$ seipone B. M. Mphele, ${ }^{2}$ shyngle K. Balogun, ${ }^{3}$ kagiso N. Tlhabano \\ ${ }^{I}$ Department of Psychology, University of Botswana Gaborone, Botswana. \\ ${ }^{2}$ Timothy O. ABODERIN,Department of Psychology, University of Ibadan, Nigeria \\ ${ }^{3}$ Correspondent: Prof Shyngle K. Balogun, Department of Psychology, University of Botswana, Botswana.
}

\begin{abstract}
This study was designed to investigate the effect of chronic administration of lead (Pb) on feeding behavior and weight gain among Wistar albino rats. 14 male subjects of randomly selected rats were used in the experiment. The rats were divided into two groups with 7 rats constituting each group. The groups are saline group and lead $(\mathrm{Pb})$ group. The lead $(\mathrm{Pb})$ administered was given orally at $10 \mathrm{mg} / \mathrm{kg}$ of body weight. In the study feeding behaviour was not significantly affected by the treatment of lead $(P b)$. However, lead $(P b)$ administration had a significant effect on weight gain at $p<.01$ while the experimental $(\mathrm{Pb})$ group had the lower mean weight signifying weight loss. This result signaled the danger in the ingestion of Lead $(P b)$ in whatever form on the health of animals (man inclusive) especially on feeding behaviour and weight gain. It was suggested that government and other concerned agencies should address how to control the ingestion of lead in areas reported to have its "epidemic" especially in Nigeria.
\end{abstract}

Key words: Lead, feeding behavior, weight gain, rats.

\section{Introduction}

Outbreak of Lead $(\mathrm{Pb})$ epidemic in the Northern part of Nigeria is no more news. The British Broadcasting Corporation (BBC) on $5^{\text {th }}$ October, 2010, announced that at least 400 children have died from Lead poisoning in Northern Nigeria. In Dakar, Senegal, Haefliger, et al., $\left(2009^{1}\right)$ reported lead poisoning among 81 individuals and 18 child deaths due to the effect of lead $(\mathrm{Pb})$ on their central nervous system. Ever since then, death, including spontaneous abortions as reported by Pilsner, et al., $\left(2009^{2}\right)$ due to this toxic substance has been on the increase. The increase is associated with alleged illegal processing of Lead $(\mathrm{Pb})$ - rich ore for gold extraction taking place inside houses.

Lead $(\mathrm{Pb})$ is one of the most toxic heavy metals and a widespread natural and occupational environmental pollutant. Its toxicity in humans and experimental animals has been well known and widely reported in several studies (Simon, Maynard \& Thomas, 200733 Schwartz \& Stewart, 2007 ${ }^{4}$; Haefliger, et al., 20095 ; Wang, Zhou, Yang, \& Wang, 2011 ${ }^{6}$; Choudhury \& Mudipalli, 20087 ; Thayer, Heindel, Butcher, \& Gallo, $2012^{8}$; Gordon, Taylor, \& Bennett, $2002^{9}$ ). Lead is a bluish-white lustrous metal, very soft, highly malleable, ductile, and a relatively poor conductor of electricity, which has been put to many applications that are used by humans over the years. It is very resistant to corrosion but tarnishes upon exposure to air. Lead is known to change gastrointestinal absorption and tissue concentrations of essential micro and macro elements, especially those present in our food (Flora, $1991^{10}$ ). Lead fulfils no essential function in the human body, it can merely do harm after uptake from food, air or water. It can cause several unwanted effects such as bone damage, kidney damage and cardiovascular dysfunction (White, 2007 $7^{11}$ ), hearing loss and tooth decay (Lanphear, 2005 ${ }^{12}$ ), cataracts (Pokras \& Kneeland, $2008^{13}$ ), impaired cognitive ability and IQ deficits in children (Choudhury \& Mudipalli, 2008; Simon, Maynard \& Thomas, 2007 ${ }^{14}$; Schwartz \& Stewart, $2007^{15}$ ), and disease susceptibility throughout the life course (Pilsner, et al., 2009 ${ }^{16}$ ) among others.

One of the popular behaviour that has greatly impacted crucial aspect of human and animal lives and which has evolved through evolution is feeding behaviour. Each species has evolved methods of searching for, obtaining and ingesting food which it can successfully consume. Feeding behaviour according to Encyclopedia Britannica is defined as any action of an animal that is directed toward the procurement of nutrients. However, it has been discovered that in contemporary times, the motivation to adoption of certain feeding behaviour is a function of factors such as a desire to gain weight or lose weight, career conformity, and career goals and so on. Research shows that some of the popular reasons people want to gain weight include self- esteem, body build, physical strength etc. Weight gain or loss has its consequences such as being overweight, loss of appetite and poor cardiovascular respiratory functions. However, the most important thing is to eat appropriately for the right kind of body structure that would aid healthy living. 
Different kinds of drug intake has been associated with activities related to food intake, weight gained/lost and water intake (e.g. Balogun, Osinowo and Idemudia, 2002 ${ }^{17}$; Moniuszko-Jakoniuk, 2003 $3^{18}$; Thayer, Heindel, Butcher and Gallo, 2012 ${ }^{19}$; Alewu and Anuka, 2009 ${ }^{20}$ ).

A study by Moniuszko-Jakoniuk $\left(2003^{21}\right)$ on lead turnover and changes in body status of chosen micro and macro elements in rats exposed to lead and ethanol found that lead alone and in combination with ethanol resulted in reduced weight gain but ethanol alone had no significant effect on body weight gained. Similar results were reported in studies by Flegal, Margaret, \& Carroll, $\left(2002^{22}\right)$ and Thayer, Heindel, Butcher, and Gallo $\left(2012^{21}\right)$ on the effect of lead on body weight gain, obesity and type 2 diabetes. Amin, VenkatakrishnaBhatt, and Panchal, $\left(1993^{23}\right)$ tested the effects of lead on anorexia and body weight in albino rats and found that there was mild to moderate changes in food consumption of rats treated with the drug. Another study by Wang, Zhou, Yang and Wang $\left(2011^{24}\right)$ found that in addition to weight gain, lead $(\mathrm{Pb})$ and/or cadmium $(\mathrm{Cd})$ ingestion significantly increased urinary flow in female rats. Other effects of drugs on either food consumption and/or body weight gain was carried out by Balogun, Osinowo and Idemudia $\left(2002^{25}\right)$ who found that alcohol and/ or nicotine reduces water and food intake, while Iyeh $\left(1999^{26}\right)$ found that food intake and body weight gain was reduced with the ingestion of alcohol and nicotine. Similar to findings by Lin, Tan, Hsu, \& Yu $\left(2001^{27}\right)$ on the association of lead and renal insufficiency, Choudhury and Mudipalli $\left(2008^{28}\right)$ reported an association between lead $(\mathrm{Pb})$ ingestion and longitudinal decline in renal functions in human beings. The conclusion arising from these studies is that humans or animals are likely to be negatively affected by inadvertent ingestion of drugs (chemical compounds) by reduction in needed body nutrients for growth or survival and this is the concern of this study. As a result of chronic ingestion of lead in the affected area of Northern Nigeria, it would be interesting to find out the effect of individuals' food intake which has consequence(s) for survival, albeit in rats as ethical issue would not permit the use of human beings.

Design:

\section{Methodology} Subjects:

The design for this study was Experimental Control Group: Randomized Subject Design.

The subjects of the study were fourteen (14) male albino rats whose initial body weight ranges from 190 - 259. They had neither laboratory experience nor previous drug history. The rats were housed individually in RB3 cages (North Kent Plastic Cages Ltd). The cages were numbered A1-A7 for the saline group, B1-B7 for the lead $(\mathrm{Pb})$ group. This is done for easy identification of each of the groups. In addition, the subjects were identified with tail ring marking with fairly indelible ink. This resulted in having two (2) groups of seven subjects each.

The experiment was carried out under normal day- night cycle. The rats had unlimited access to food and water 24 hours daily. They were, however, deprived of food and water during 1 hour of drug administration and data collection. Rat pellets which were measured and weighed in cellophane bags constituted their food, which was made available to the rats through a food hopper and water by means of special water bottles designed for rats.

\section{Drug Preparation:}

Laboratory lead $(\mathrm{Pb})$ solution used was diluted with saline solution, because the concentration of the original solution was too high for the rats.

\section{Procedure:}

The rats were first placed in their cages for 5 weeks to acclimatize before the commencement of the experiment. During this period, food and water were freely available without any form of deprivation. At the end of the orientation period, there was also a 1 week base line period before the treatment and another 1 week base line after the treatment, this was undertaken so as to erase any plausible explanation for the outcome of the study. The order of injection was first the control group and then the experimental rats. The control group was treated with saline solution (placebo). Lead $(\mathrm{Pb})$ solution and saline were administered to the experimental group with the oral cannula. The volume of lead $(\mathrm{Pb})$ and saline administered to the rats depend on the body weight of the rats. However, after treating the rats according to their group each day, 30 minutes rest was allowed so that the drugs will be properly and effectively ingested into the system before introducing them to water and food. This condition was applied throughout the experiment period.

Recording and data collection commenced the next day an hour before the treatment stopped so as to allow for a 23 hour effect. Quantity intake was determined by subtracting the weight of the food remaining and spillage from the previous day food given. On the other hand, weight gain was determined by subtracting the weight of the previous day before administration from the weight of the new day after administration. The 
importance of weighing the rats on a daily basis is to determine their individual drug dosage and also to determine the amount of weight loss or gain after the administration of the drug.

\section{Analysis Of Data And Results}

It was predicted that lead $(\mathrm{Pb})$ administration will significantly affect the feeding behaviour of rats. This was tested using $\mathrm{T}$-test for the independent samples by comparing the means of quantity of food consumed between the control group and the experimental group. The result is presented on table 1 .

Table 1: Summary of T- test showing the Effect of Lead (Pb) Administration on Feeding Behaviour of Albino Rats.

\begin{tabular}{|c|c|c|c|c|c|c|}
\hline Feeding Behaviour & $\mathrm{N}$ & $\overline{\mathrm{X}}$ & $\mathrm{SD}$ & $\mathrm{Df}$ & $\mathrm{t}$ & $\mathrm{P}$ \\
\hline Saline Group & 7 & 23.09 & 6.10 & 12 & .860 & $>.05$ \\
\hline Lead Group & 7 & 22.25 & 3.79 & \multicolumn{3}{|l}{} \\
\hline
\end{tabular}

From table 1, it can be deduced that, there is no significant difference in the means of quantity of food consumed between the control group and the experimental group; the results indicate that, lead $(\mathrm{Pb})$ administration had no significant effect on feeding behaviour of rats. (Experimental mean $=22.25)$; (control mean=23.09); $\mathrm{df}=(12) ; \mathrm{t}=.860 ; \mathrm{p}>.05$. Therefore, the results suggest that lead $(\mathrm{Pb})$ administration did not significantly account for variance in feeding behaviour of rats in this study. A closer observation would note that there was a reduction in food intake by rats treated with lead but this was not significant enough to be attributed to the lead ingestion. Hence, the tested hypothesis is not confirmed or rejected.

It was also predicted that Rats in the control group will significantly gain more weight than rats in the experimental group. This was tested using T-test for independent samples and the results are presented on table .2

Table 2: T- test for Independent Showing the Effect of Lead (Pb) Administration on Weight Gain of Rats.

\begin{tabular}{|c|c|c|c|c|c|c|}
\hline Weight Gain & $\mathrm{N}$ & $\overline{\mathrm{X}}$ & $\mathrm{SD}$ & $\mathrm{Df}$ & $\mathrm{t}$ & $\mathrm{P}$ \\
\hline Saline Group & 7 & 245.75 & 19.05 & 12 & 3.742 & $<.01$ \\
\hline Exp. Group & 7 & 232.73 & 16.21 & \multicolumn{3}{|l|}{} \\
\hline
\end{tabular}

The results presented in table 2 indicates that there is a statistical difference in weight gain between control group and experimental group at the treatment level which was confirmed at $\mathrm{df}(12) ; \mathrm{t}=3.742 ; \mathrm{p}<.01$. Control group $($ mean $=245.75)$ and experimental group $($ mean= 232.73). The results imply that, the significant mean difference between the groups was as a result of lead $(\mathrm{Pb})$ administration to the experimental group. This follows from the first hypothesis that since the lead group was not eating as much, there is bound to be a reduction in their weight. Therefore, lead $(\mathrm{Pb})$ administration significantly affects the weight of the rats.

\section{Discussion And Conclusion}

In this section, the discussion of the results of the study were presented in line with the stated hypotheses and supported with previous studies.

It is instructive to note, however, that it is the present belief that both moderate and strong effects are to be expected in both animals and human subjects when permissive dose of lead $(\mathrm{Pb})$ is administered to them.

This belief in terms of the moderate dose was justified by the result of this study, when a moderate dose of lead $(\mathrm{Pb})(10 \mathrm{mg} / \mathrm{kg})$ was administered to male albino rats to find out its effects on feeding behaviour and weight gain.

It was observed that as the lead ingested by the rats increased (Chronic ingestion), there was reduction in their food intake In support of this finding, Moniuszko- Jakoniuk (2003) reported that feeding behaviour of rats exposed to lead $(\mathrm{Pb})$ was lowered by $16 \%$. The results of this study are also in agreement with the findings of Czech, D. A. et al. $\left(1976^{26}\right)$ which asserted that lead $(\mathrm{Pb})$ significantly depressed food intake at dosage levels of 7,10 and $13 \mathrm{mg} / \mathrm{kg}$. Although the present study did not report a significant effect of lead intake on feeding behaviour, which has support in the study of Mahaffey $\left(1977^{27}\right)$, the fact that a difference was even noticed is suggestive enough to sound a note of warning as weight reduction was significantly affected.

It is important to note that, previous studies have reached different and sometimes opposing conclusions about the effects of chronic administration of lead $(\mathrm{Pb})$ on feeding behaviour and weight gain among Wistar albino rats. Studies on lead consumption are, however, limited in this part of the world (Nigeria) or experimentally tested on living organism as done in the present study. 
V.

\section{Conclusion}

In conclusion, the fact that the results of this study on the effect of chronic administration of lead $(\mathrm{Pb})$ use do not have any significant effect on feeding behaviour but on weight gain is not a criterion for the continuous use of lead $(\mathrm{Pb})$. Lead $(\mathrm{Pb})$ has been recognized as a developmental neurotoxicant that can interfere with the developing brain, resulting in functional impairment. Recent evidence has also revealed other important health effects of lead $(\mathrm{Pb})$ exposure, such as cardiovascular outcomes, renal disease and decreased fertility. In other words, lead $(\mathrm{Pb})$ exposure could be harmful both to the central nervous system and the adrenal gland. Now that an "epidemic" of it is reported in Northern Nigeria, It would save the nation a lot of trouble if its control can be addressed quickly to prevent further deaths and concomitant/ related ill health cases associated with lead ingestion.

\section{References}

[1]. Alewu, B. \& Anuka J. A.). Toxicological effects of carbofuran on the water and food intake in albino Wistar rat. The Inter. J. Toxicol. 2009. 7(1), $45-50$.

[2]. Amin, R. J., Venkatakrishna- Bhatt, H., \& Panchal, G.M.. Effect of lead (Pb) on anorexia and body weight in albino rats. J. Phys. Pharm. 1993. 37 (2) pp. 155- 200.

[3]. Balogun, S. K., Idemudia, S. E., \& Osinowo, H. O. The effects of separate and combined chronic ingestion of alcohol and nicotine on body weight albino rats. J. Psych. Stud. 2002.3 (1): 75- 82.

[4]. Choudhury, H. \& Mudipalli, A. Potential considerations \& concerns in the risk characterization for interaction profiles of metals. Ind. J. Med. Res. 2008.. 128, 462-483.

[5]. Czech, D. A., Schmidt, J. C. \& Stone, J. M. Effect of tetraethyl lead on food intake and water. J. Inform. 1976. 5(4), 387-389.

[6]. Flegal, K M.; Margaret D., \& Carroll, M.S. Prevalence and trends in obesity among US adults 1999-2000. JAMA, 2002.288 (14): 17231727.

[7]. Flora, S. J. S., Kumar D., Sachan S. R. S., et.al. Combined exposure to lead and ethanol on tissue concentration of essential metals and some biochemical indices in rat. Biol. Trac.. Elem. Res. 1991.28, 157,

[8]. Gordon J. N., Taylor A., \& Bennett P. N.. Lead poisoning: Case studies. Brit. J. Clin. Pharm. 2002 53, 451,

[9]. Haefliger, P., Mathieu-Nolf, M., Lociciro, S., et.al.. Mass lead intoxication from informal used lead-acid battery recycling in Dakar, Senegal. Envir. Health Persp. 2009. Vol. 117(10), pp. 1535-1540.

[10]. Iyeh, E. T. Effect of chronic administration of alcohol and nicotine

[11]. (combined) on feeding behaviour and weight gain. Unpublished B.Sc. thesis, 1999. University of Ibadan, Nigeria

[12]. Lanphear, B. P., Hornung, R., Khoury, J., et al.. Low-level environmental lead exposure and children's intellectual function: An international pooled analysis. Envir. Heal. Pers. 2005.113 (7): 894-9.

[13]. Lin, J.L., Tan D. T., Hsu, K. H., et.al.. Environmental lead exposure and progressive renal insufficiency. Arch. Intern. Med., 2001.161, 264.

[14]. Lin, W., Zhou, X., Yang, D. \& Wang, Z. Effects of lead and/ or cadmium on the distribution patterns of some essential elements in immature female rats. Hum. Exp.l Toxicol. 2011.30(12) 1914- 1923.

[15]. Mahaffey, K. R. Effects of concurrent administration of lead, cadmium and arsenic in the rat. J of Biochem. Pharm. 1977. 41, 485 489

[16]. Moniuszko- Jakoniuk . Lead ( $\mathrm{Pb})$ turnover and changes in the body status of

[17]. chosen micro and macro elements in rats exposed to lead and ethanol.

[18]. Pol. J. Envir. Stud. 2003. 12(3), 335- 344.

[19]. Pilner, J. R., Hu, H., Ettinger, A., et.al. Influence of prenatal lead exposure on genomic methylation of cord blod DNA. Envir. Heal. Pers., 2009. 117 (9), pp.1466-1472.

[20]. Pokras, M. A. \& Kneeland, M. R. Lead poisoning: Using transdisciplinary

[21]. approaches to solve an ancient problem. EcoHealth, 2008. 5 (3): 379-85.

[22]. Schwartz, B. S. \& Stewart, W. F. Lead and cognitive function in adults: A question and answers to a review of the evidence of cause, treatment, and prevention. Inter. Rev. Psych. 2007. 19(6) 671-692.

[23]. Simon, D. L., Maynard, E. J., \& Thomas, K. D. . Living in a sea of lead: Changes in blood- and hand-lead of infants living near a smelter. J. Exp. Sci. Envir. Epid. 2007. 17(3) 248- 259.

[24]. Thayer, K. A., Heindel, J. J. \& Gallo, M. A. Role of environmental chemicals in diabetes and obesity: A national toxicology program workshop review. Envir. Heal. Pers. 2012. 120 (6), 779-789.

[25]. White, L. D., Cory-Slechta, D. A., Gilbert, M. E., et al. . New and evolving concepts in the neurotoxicology of lead. Toxicol. Appl. Pharm.. 2007. 225 (1): 1-27. 